\title{
Occlusion of retinal capillaries caused by glial cell proliferation in chronic ocular inflammation
}

\author{
E. Bianchi ${ }^{1}$, G. Ripandelli ${ }^{2}$, J. Feher ${ }^{1,3}{ }^{3}$, A.M. Plateroti ${ }^{1}$, R. Plateroti ${ }^{1}$, I. Kovacs ${ }^{4}$, \\ P. Plateroti ${ }^{1}$, S. Taurone ${ }^{1}$, M. Artico ${ }^{1}$ \\ ${ }^{1}$ Department of Sensory Organs, Sapienza University of Rome, Italy \\ ${ }^{2}$ Bietti Eye Foundation, Rome, Italy \\ ${ }^{3}$ Ophthalmic Neuroscience Program, Nutripharma Hungaria Ltd., Budapest, Hungary \\ ${ }^{4}$ Department of Ophthalmology, Semmelweiss University of Budapest, Hungary \\ [Received 23 March 2014; Accepted 9 April 2014]
}

\begin{abstract}
The inner blood-retinal barrier is a gliovascular unit in which glial cells surround capillary endothelial cells and regulate retinal capillaries by paracrine interactions. During chronic ocular inflammation, microvascular complications can give rise to vascular proliferative lesions, which compromise visual acuity. This pathologic remodelling caused by proliferating Müller cells determines occlusion of retinal capillaries. The aim of the present study was to identify qualitative and quantitative alterations in the retinal capillaries in patients with post-traumatic chronic ocular inflammation or post-thrombotic vascular glaucoma. Moreover, we investigated the potential role of vascular endothelial growth factor (VEGF) and pro-inflammatory cytokines in retinal inflammation. Our electron microscopy findings demonstrated that during chronic ocular inflammation, thickening of the basement membrane, loss of pericytes and endothelial cells and proliferation of Müller cells occur with irreversible occlusion of retinal capillaries. Angiogenesis takes place as part of a regenerative reaction that results in fibrosis. We believe that VEGF and pro-inflammatory cytokines may be potential therapeutic targets in the treatment of this disease although further studies are required to confirm these findings. (Folia Morphol 2015; 74, 1: 33-41)
\end{abstract}

Key words: basement membrane, electron microscopy, Müller cells, immunohistochemistry, VEGF, PEDF, IL-1 $\beta, \operatorname{TNF} \alpha, \operatorname{TGF} \beta 1$

\section{INTRODUCTION}

The blood-retinal barrier (BRB) consists of inner and outer components and plays an important role in the homeostatic regulation of the retinal microenvironment. The inner BRB is formed by the tight junctions between neighbouring capillary endothelial cells [47], which rest on a basal lamina covered by the processes of astrocytes and Müller cells [5]. Pericytes, separated from the endothelial cells by the basal lamina, together with Müller cells, contribute to the proper functioning of the inner BRB [32]. The outer BRB is formed by tight junctions between cells of the retinal pigment epithelium [19], which play an important role in trasporting nutrients from the blood to the outer retina. Chronic ocular inflammation can occur as a consequence of age progression [16], disease, injury and surgery $[23,42,50]$. Inflammation is typically associated with an increase in production of pro-inflammatory mediators [17], such as cytokines and chemokines, and persistent inflammation can lead to impaired vision and blindness [59]. Fibroblasts play crucial roles in both inflammation and wound healing, producing pro-inflammatory mediators in response to injury and inflammatory stimuli $[7,49]$. Epithelial

Address for correspondence: Prof. M. Artico, Department of Sensory Organs, "Sapienza" University of Rome, V.le del Policlinico 155 00161 Rome, Italy, tel: +39 06 49976755, fax: +39 06 49976817, e-mail: marco.artico@uniroma1.it 
cells and macrophages produce a pro-inflammatory cytokine, interleukin-1 beta (IL-1 $\beta$ ), that increases the fibroblastic production of cytokines and chemokines, and vascular endothelial growth factor (VEGF) [11, 43]. Monocyte chemoattractant protein (MCP)-1, IL-6 and IL-8 produced by fibroblasts, promote immune cell infiltration [49]. VEGF is the most important factor in promoting angiogenesis, the sprouting of new capillaries from pre-existing blood vessels, a regulated process essential in reproduction, development and tissue repair [11]. Müller cells, the glial cells of the retina, constitute a functional link between neurons and vessels. These glial cells support neurons with blood-derived nutrients, remove metabolic waste and maintain the homeostasis of the retinal extracellular ions, water, neurotransmitter molecules and $\mathrm{pH}[14,52]$. Indeed, under inflammatory and hypoxic conditions these glial cells secrete factors such as VEGF, that increase the vascular permeability $[2,56]$, and matrix metalloproteinases $[10,36]$, which impair the barrier function of retinal endothelial cells. Under normoxic conditions, Müller cells secrete pigment epithelium-derived factor (PEDF) that decreases the barrier permeability and downregulates the expression of VEGF [12, 22]. VEGF is known to modulate immune responses by increasing vascular permeability. Because of its pro-inflammatory actions it enhances the adhesion of leucocytes to vascular walls and increases the levels of intercellular cell adhesion molecule-1 (ICAM-1) and vascular cell adhesion molecules-1 [31]. Up-regulation of ICAM-1 in the vascular endothelium induces an accumulation of leucocytes within the retina [29, 39]. Leucocyte adhesion to the endothelium and migration into the tissues [48], mediated by ICAM-1, results in injury to endothelial cells followed by increased retinal vascular permeability, retinal oedema and loss of visual acuity [29]. A previous study showed that human Müller cells produced IL- 6 after stimulation with either IL- $1 \beta$ or lipopolysaccharide and IL-6 production may have an important role in various conditions involving ocular inflammation [57]. Pro-inflammatory cytokines, such as IL-1 $\beta$, IL- 6 and tumour-necrosis factor alpha (TNF $\alpha$ ) have been detected in the retinas of rats with diabetes $[15,40]$. Under high-glucose conditions, Müller cells rapidly produce IL-1 [54], TNF $\alpha$ and IL-6. Studies using drugs with anti-inflammatory properties have shown that such treatment is able to prevent the development of diabetic retinopathy $[33,40]$.

The aim of this study was to identify by electron microscopy alterations which occur in the capillaries as a result of chronic ocular inflammation caused by glial cell proliferation. We investigated the expression of these growth factors and pro-inflammatory cytokines to shed light on the etiopathogenesis of ocular chronic inflammation, which may have significant clinical consequences in terms of pharmacological treatment. It may play a key role in developing new non-surgical forms of treatment to reduce the severity of inflammation, angiogenesis and retinal capillary occlusion caused by Müller cells.

\section{MATERIALS AND METHODS}

\section{Ethical considerations}

Thirty enucleated human eyes (age range 38-81 years, $18-6$ female and 3 male patients - with ocular inflammatory disease and $12-4$ female and 2 male patients - with glaucomatous eyes), were selected for these electron microscopic studies. Patients with inflammatory ocular disease had a moderate to severe grade of inflammation. Samples of retina were harvested from the left eye during autopsies. Since post-mortem phenomena may produce early morphologic modifications of the eye structure, our samples were harvested as early as possible after death (within $24 \mathrm{~h}$ ). The protocol and informed written consent forms were approved by the Ethical Committee of the "Sapienza" University of Rome and G.B. Bietti Eye Foundation (IRCCS). Before signing the informed consent form, patients were informed about the study in detail by a physician providing them by ample time to ask possible questions. The study was conducted in accordance with the Declaration of Helsinki.

\section{Electron microscopy}

The ocular tissues were fixed immediately in buffer containing $2 \%$ glutaraldehyde for $2 \mathrm{~h}$, washed and then postfixed in buffer $2 \%$ osmium tetroxide for $2 \mathrm{~h}$, dehydrated and embedded in araldite. Ultrathin sections were made using a Reichert Ultra-microtome. These sections were counterstained by uranyl acetate and lead citrate and studied with Zeiss EM 109 electron microscope.

\section{Immunohistochemical analysis}

Control morphological sections were stained with haematoxylin-eosin (not shown). The following molecules were investigated: VEGF, PEDF, IL-1 $\beta$, TNF $\alpha$ and transforming growth factor beta (TGF $\beta 1$ ).

Small fragments of retina taken from the post-traumatic chronic ocular inflammation or post- 
-thrombotic vascular glaucoma patients were washed in phosphate buffered saline (PBS), fixed in $10 \%$ formalin and embedded in paraffin according to a standard procedure. The method employed for immunohistochemical tests was $A B C / H R P$ technique (avidin complexed with biotinylated peroxidase). Serial 3- $\mu \mathrm{m}$ thick sections were cut using a rotative microtome, mounted on gelatin-coated slides and processed for immunohistochemistry. These sections were deparaffinised in xylene and dehydrated. They were immersed in citrate buffer $(\mathrm{pH} 6)$ and subjected to microwave irradiation twice for $5 \mathrm{~min}(750 \mathrm{~W})$. Subsequently, all sections were treated for $30 \mathrm{~min}$ with $0.3 \%$ hydrogen peroxide in methanol to quench endogenous peroxidase activity. To block non-specific binding, the slides were incubated in $6 \%$ normal goat serum in PBS for $30 \mathrm{~min}$ at room temperature. The slides were incubated overnight at $4^{\circ} \mathrm{C}$ with primary mouse monoclonal antibodies (dilution: 1/100) against human VEGF (Santa Cruz, sc-53462), against human TNF $\alpha$ (Santa Cruz, sc-52746) and with primary rabbit polyclonal antibody against human IL-1 $\beta$ (Santa Cruz, sc-7884), against human PEDF (Santa Cruz, sc-25594) and against human TGF $\beta 1$ (Santa Cruz, sc146). Optimal antisera dilutions and incubation times were assessed in a series of preliminary experiments. After exposure to the primary antibodies, slides were rinsed twice in phosphate buffer and incubated for $1 \mathrm{~h}$ at room temperature with the appropriate secondary biotinylated goat anti-mouse or anti-rabbit IgG (vector laboratories Burlingame, CA, USA, BA9200 and $B A 1000)$ and with peroxidase-conjugated avidin (Vector laboratories, Burlingame, CA, USA, Vectastain Elite ABC Kit Standard* PK 6-100) for 30 min. After a further wash with phosphate buffer, slides were treated with $0.05 \%$ 3,3-diaminobenzidine and $0.1 \% \mathrm{H}_{2} \mathrm{O}_{2}$. Finally, sections were counterstained with Mayer's haematoxylin and observed using a light microscope. Negative control experiments were done: (i) by omitting the primary antibody; (ii) by substituting the primary antibody with an equivalent amount of non-specific immunoglobulins; (iii) by pre-incubating the primary antibody with the specific blocking peptide (antigen/antibody $=5$ according to supplier's instructions). The staining assessment was made by 2 experienced observers in light microscopy. We assessed the immunoreactivity for VEGF, PEDF, TGF $\beta 1$; IL-1 $\beta$, TNF $\alpha$ in the retina. The intensity of the immune reaction was assessed microdensitometrically using an IAS 2000 image analyser (Delta Sistemi, Rome,

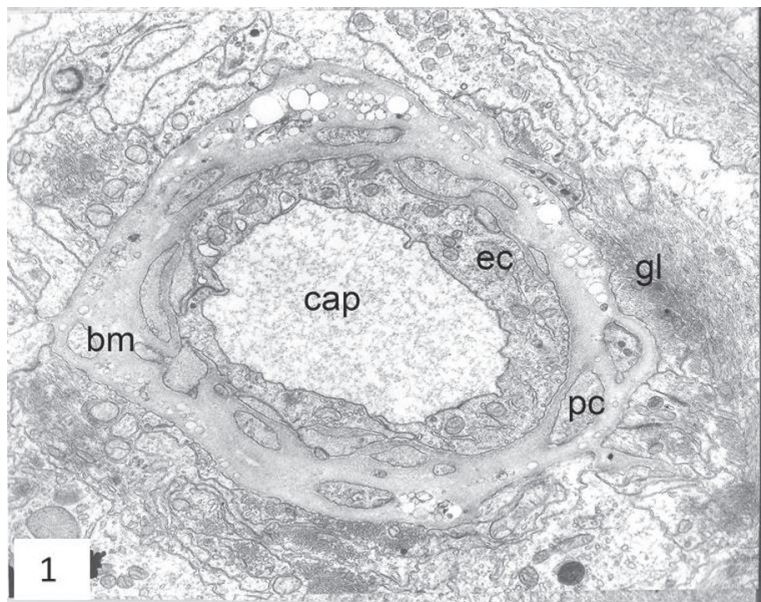

Figure 1. Transmission electron microscopy of a normal aged retinal capillary (cap). Well preserved endothelial cells (ec) show normal appearance mitochondria, endoplasmic reticulum, Golgi apparatus and several pinocytotic vesicles adjacent to the plasma membrane. External layer of capillary basement membrane (bm) is significantly thickened and contains only a few processes of pericytes (pc) but several electro-translucent vacuoles. The capillary is surrounded by numerous glial cells (gc); 71-year-old man; magnification: $20,000 \times$.

Italy) connected via a TV camera to the microscope. The system was calibrated taking the background obtained in sections exposed to non-immune serum as zero. Ten $100 \mathrm{~mm}^{2}$ areas were delineated in each section by a measuring the diaphragm.

\section{RESULTS}

\section{Electron microscopy}

Transmission electron microscopy (TEM) examination of the retinas taken from patients with chronic ocular inflammation showed the lumen of retinal capillaries to be completely occluded by glial cells and increased thickening of the capillary basement membrane (BM) with some electro-dense granules, compared with those of the control patients. TEM examination of the cross sections of normal human retinal capillaries (age 71-80 years old) showed well preserved endothelial cells with apparently normal mitochondria, endoplasmic reticulum, Golgi apparatus and several pinocytotic vesicles adjacent to the plasma membrane. The external layer of the capillary BM was significantly thickened, containing only a few processes of pericytes but several electro-translucent vacuoles. The retinal capillaries were surrounded by numerous glial cells (Fig. 1). The BM consisted of: an inner subendothelial BM interposed between endo- 


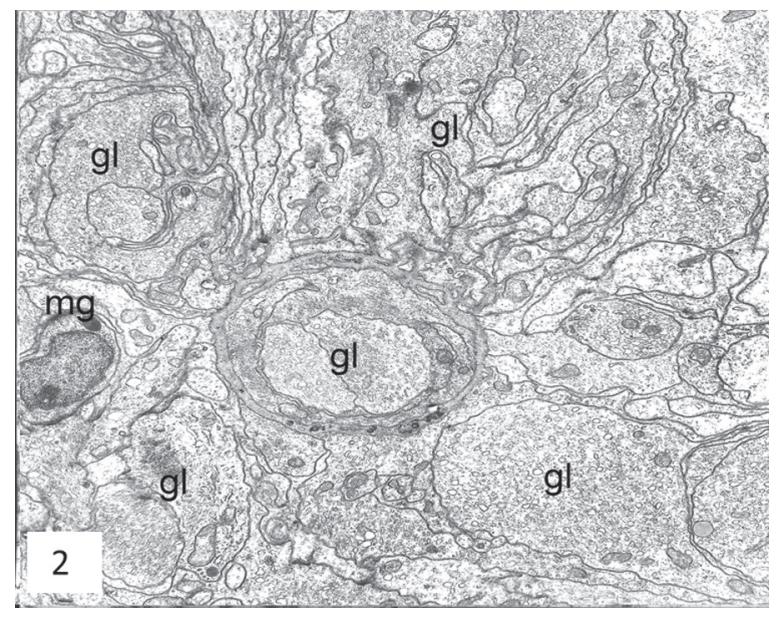

Figure 2. Post-traumatic chronic inflammation of the retina. An occluded retinal capillary can be seen in the central area of this picture. The retina contains mainly glial cells ( $\mathrm{gl})$, and a microglia $(\mathrm{mg})$ can also be seen; 38-year-old man; magnification: 14,000×.

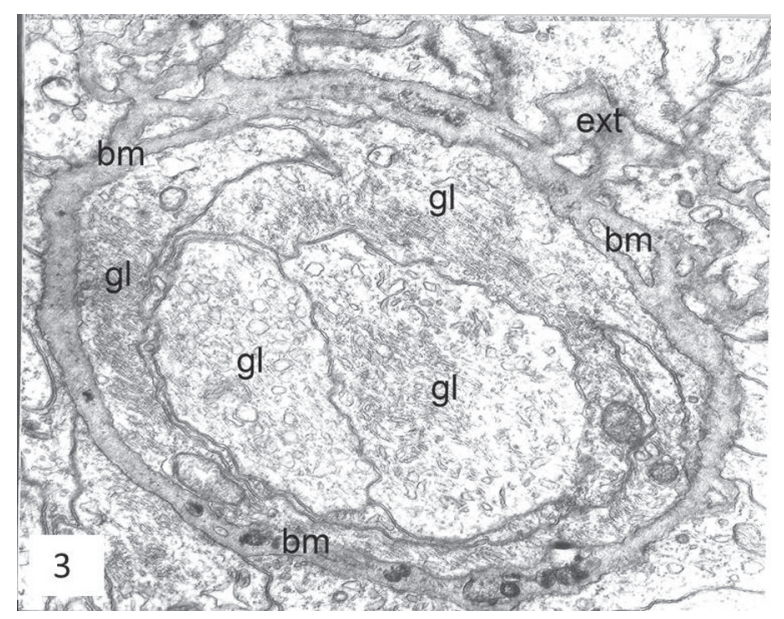

Figure 3. Higher magnification of the previous picture. Capillary lumen is occluded by several processes of glial cells (gl), which contains numerous microtubule and a very few organelles. Endothelial cells are absent. Capillary wall is formed mainly by slightly thickened basement membrane (bm), which contains a few cytoplasmic processes of pericytes but some electro-dense granules, probably lipids. In several places capillary basement membrane forms extensions into the intercellular places (ext); 38-year-old man; magnification: $34,000 \times$.

thelial cells and pericytes, and an external BM placed between the pericytes and Müller glial cells. TEM examination of retinas removed from post-traumatic chronic ocular inflammation or post-thrombotic vascular glaucoma patients showed increased thickening of the capillary BM compared with those of the controls. The lumen of the capillaries was occluded by several processes of glial cells, containing numerous

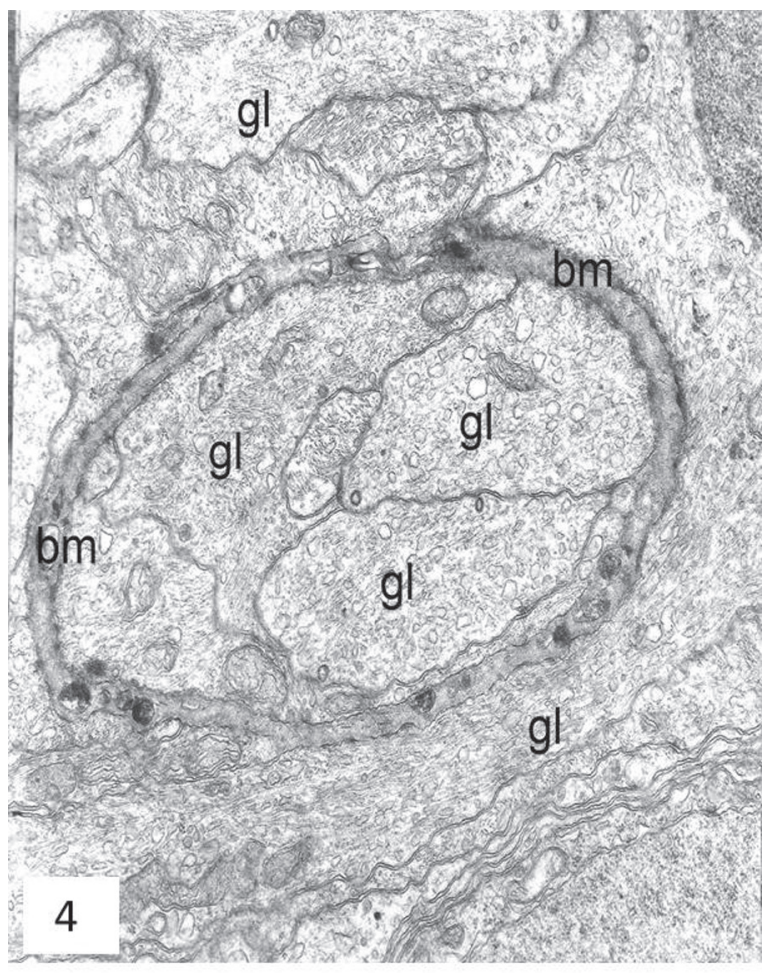

Figure 4. Another occluded retinal capillary of the same eye. Capillary lumen is completely occluded by glial cell ( $\mathrm{gl}$ ), endothelial cells and pericytes are absent, capillary basement membrane (bm) is slightly thickened and contains some electro-dense granules, the surrounding retina is replaced by glial cells; 38 -year-old man; magnification: $30,000 \times$.

microtubules and a few organelles. Endothelial cells and pericytes were absent (Figs. 2, 3). The capillary walls were formed mainly by a slightly thickened BM, containing a few cytoplasmic processes of pericytes but some electro-dense granules and vacuoles (Figs. 4, 5). These data indicate that chronic ocular inflammation, caused by trauma or thrombotic vascular glaucoma, is followed by an immediate increase in capillary permeability accompanied by retinal oedema. This functional capillary change is followed by structural damage to the capillary wall. Thrombus formation occurred in the damaged vessels, thus producing areas of stasis and associated retinal haemorrhages. Finally, there is a complete loss of the capillary endothelium and pericytes, and acellular capillaries are invaded by proliferating glial cell processes, thus producing permanent capillary closure. These processes of glial cells, surrounded by some remnants of plasma or erythrocytes, occasionally fill the whole capillary lumen. The processes of Müller cells enter the capillary lumen through small gaps in the BM, and often the spaces formerly occupied by pericytes 


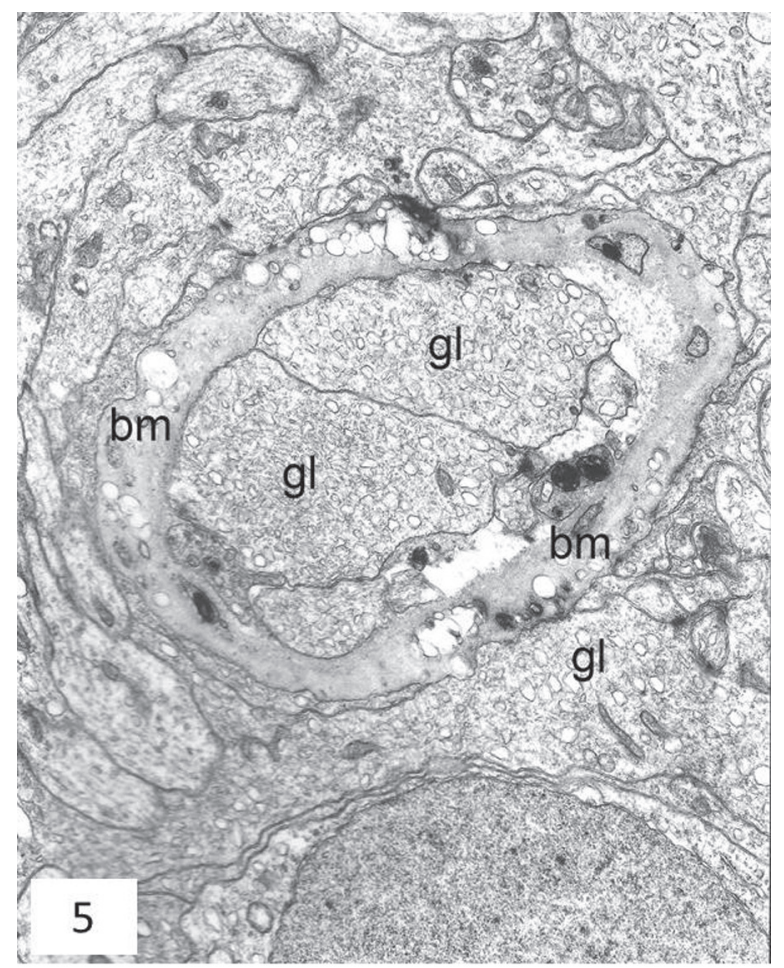

Figure 5. Occluded retinal capillary in post-thrombotic vascular glaucoma. Capillary lumen is occluded by glial cells $(\mathrm{gl})$, basement membrane (bm) significantly thickened and contains numerous vacuoles and electro-dense granules; 81-year-old women; magnification 25,000×.

were often also filled by glial cells. The glial cells inside the capillaries usually contain smooth endoplasmic reticulum, some ribosomes, microfilaments, small mitochondria, vesicles of lipid and, occasionally, the cells have the appearance of macrophages.

\section{Immunohistochemical analysis}

Under light microscope, fragments of retina from post-traumatic chronic ocular inflammation or post-thrombotic vascular glaucoma patients were examined. Sections of retina of chronic ocular inflammation patients exposed to the primary/secondary antibodies developed a dark-brown (intense), yellow-brown (slight) or no appreciable immunostaining.

VEGF immunoreactivity was observed in cells infiltrating the subretinal space. Immunoreactivity for VEGF was observed in the detached retina and dilated vessels (Fig. 6). There were no significant correlations between VEGF immunoreactivity in retinal endothelial cells and the presence of retinal vascular abnormalities. In contrast, normal retinae did not contain macrophage infiltration or vascular abnormalities. VEGF immunoreactivity was not observed in the blood vessels situated in the normal retina (data not shown).

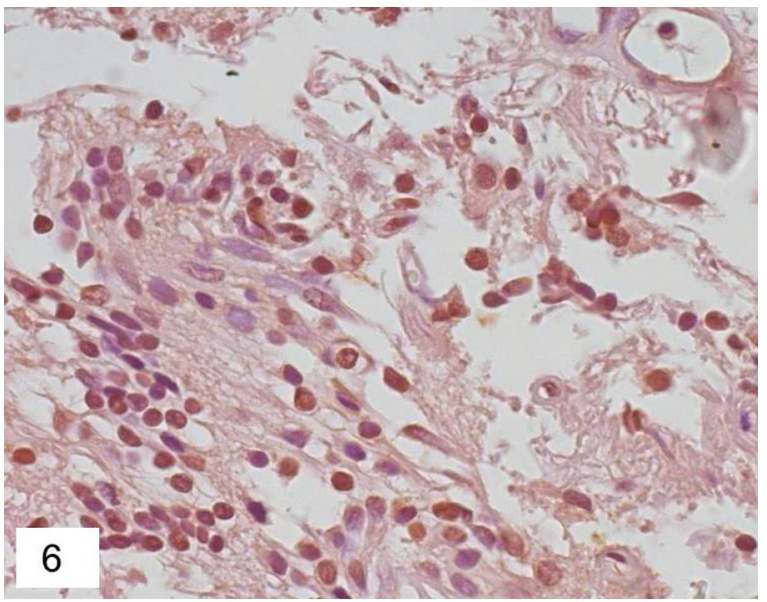

Figure 6. Immunohistochemical analysis of human retina for vascular endothelial growth factor (VEGF). VEGF stain of human retina section shows a cytoplasmic localisation in the inner nuclear layer. VEGF immunoreactivity was expressed in cells infiltrating the subretinal space and in the blood vessels $(40 \times)$.

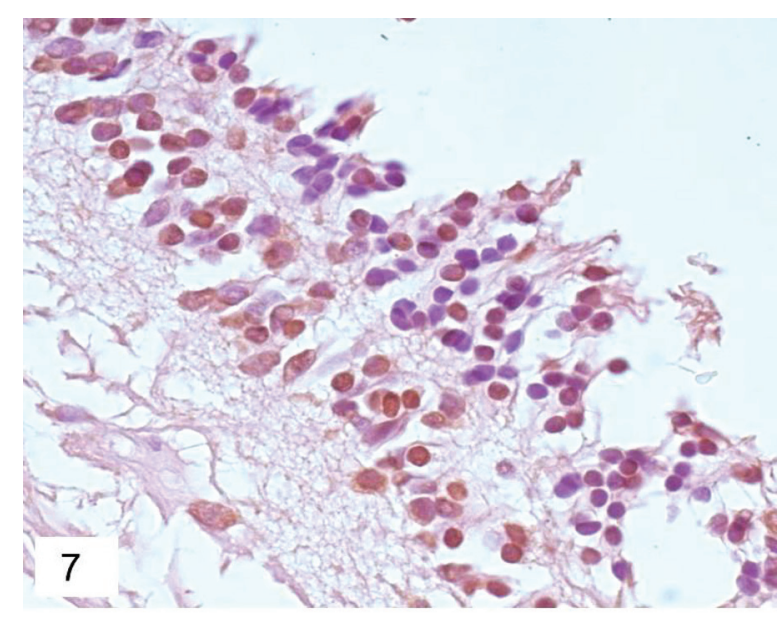

Figure 7. Immunohistochemical analysis of human retina for pigment epithelium-derived factor (PEDF). PEDF immunoreactivity was positive in the retinal pigment epithelial layer, but was rarely positive in the cytoplasm of other retinal cells $(40 \times)$.

Cytoplasmic immunoreactivity for VEGF was weakly noted in the inner nuclear layer. An intense reaction for PEDF was seen in the inner/outer segments in the acellular zone containing rods and cones (Fig. 7). The reaction was primarily positive in the retinal pigment epithelial layer, but was rarely positive in the cytoplasm of other retinal cells. PEDF positive cells were detected to some degree in all specimens (pathologic and control), PEDF showed a weak immunoreactivity in the new vessels where fibrosis was prominent but strong immunoreactivity for PEDF was detected in 


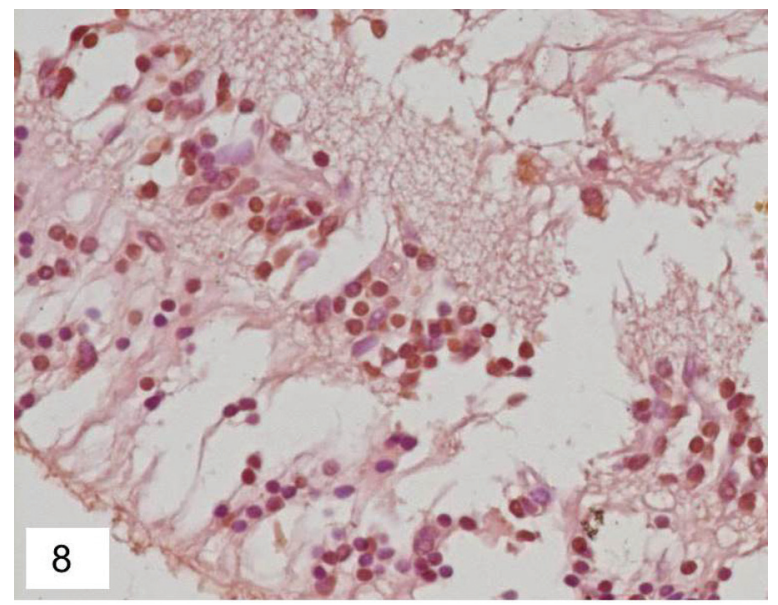

Figure 8. Strong immunostaining for interleukin-1 beta (IL-1 $\beta$ ) was observed in the ganglion cell layer, the inner nuclear layer and in the retinal pigment epithelium $(40 \times)$.

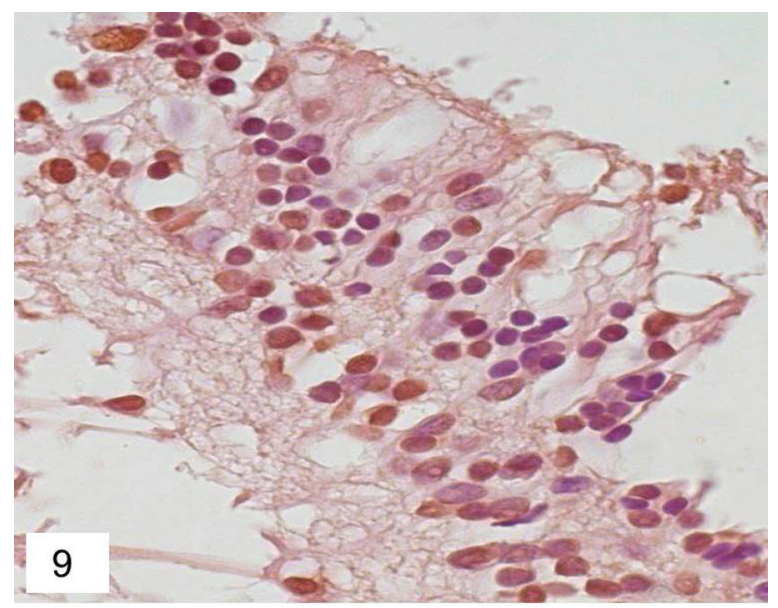

Figure 9. Immunohistochemical analysis of human retina for tumour-necrosis factor alpha (TNF $\alpha$ ). Staining for TNF $\alpha$ was observed on the retinal vascular endothelium, on infiltrating cells and on the extracellular matrix $(40 \times)$.

the retinal pigment epithelium cells. Strong immunostaining for IL-1 $\beta$ was observed in the ganglion cell layer, the inner nuclear layer and in the retinal pigment epithelium (Fig. 8). IL-1 $\beta$ can induce retinal perivascular macrophage activation Furthermore, IL-1 $\beta$ appears to be involved in the disruption of BRB in diabetic retinopathy. Staining for TNF $\alpha$ was observed on the retinal vascular endothelium, on infiltrating cells and on the extracellular matrix of 9 samples, furthermore is widely distributed within fibrovascular membranes (Fig. 9). Immunohistochemical labelling for TGF $\beta 1$ is associated with endothelial, mural and

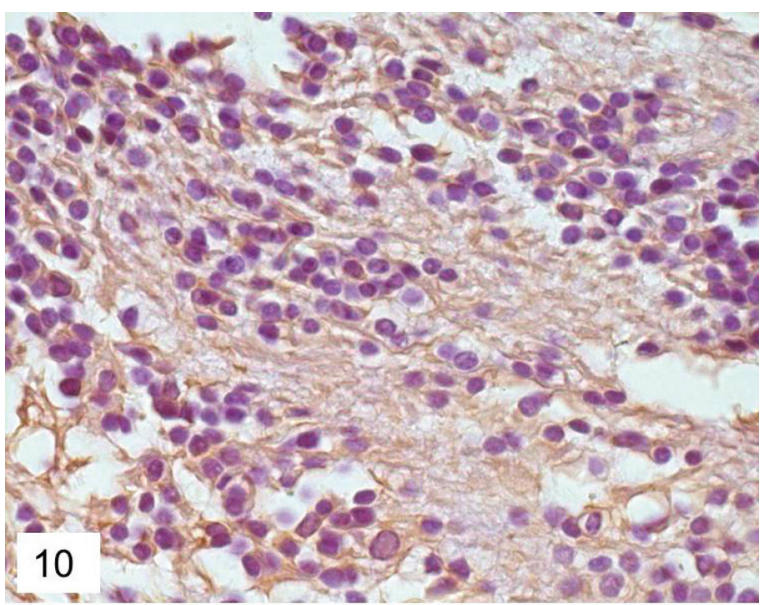

Figure 10. Immunohistochemical analysis of human retina for transforming growth factor beta (TGF $\beta 1$ ). TGF $\beta 1$ immunoreactivity was expressed in endothelial cells of the human retinal microvasculature, mural and microglial cells $(40 \times)$.

microglial cells (Fig. 10). Our findings reveal the existence of a consecutive TGF $\beta 1$ signalling in human retina required for the survival of both vascular and neural cells. These findings are consistent with the expression of TGF $\beta 1$ by pericytes and endothelial cells of the human retinal microvasculature. Further, these observations support our hypothesis that the relatively high ratio of pericytes to endothelial cells in the retina, compared to other vessel beds, should lead to significant activation of latent TGF $\beta$ 1.

\section{DISCUSSION}

Electron microscopic observation visualised the morphological changes in the retinal capillaries detected during chronical ocular inflammation. Assessment of electron microscopy confirmed the occluded state of the retinal capillaries by glial cells in patients suffering from post-traumatic chronic ocular inflammation or post-thrombotic vascular glaucoma. Recent studies have identified several possible cellular changes which may contribute to the pathogenesis of vascular leakage in inflammation [45]. Vascular damage in the retinal specimens was accompanied by intracellular retinal oedema [6]. The earliest morphological change detected in the capillaries was flattening of some of vessels and the formation of a slit-like lumen. The flattened capillaries were usually found in the deeper layers of the retina and occasionally appeared to be were compressed by the surrounding oedema [4]. The flattened appearance of the retinal capillaries was accompanied by more specific degeneration 
of the endothelium and pericytes. These capillaries showed an increased number of vacuoles appeared in the cells, thin and electrodense endothelium and endothelial gaps. Necrosis of the capillary endothelium and the resulting exposure of the BM resulted in the formation of platelet thrombi. Thus, capillary degeneration leads to the formation of areas of complete stasis in the microvasculature. After the first appearance of thrombi in the capillaries there was clearly stasis in the small vessels and many capillaries were filled with packed erythrocytes. Degeneration of the endothelium and pericytes appeared to proceed rapidly in the anoxic conditions associated with stasis $[3,18]$. The closed state of retinal capillaries probably became irreversible once of proliferating glial cells processes head entered the ghost vessels. Gaps in the BM which allowed entry of glial cells were seen infrequently, and the BM appeared to be resistant to degenerative changes. Probably, the Müller cell processes entered the vessels through the same gaps which had permitted the earlier haemorrhages [28]. Our observations confirmed functional and later structural changes in the retinal capillaries during chronic ocular inflammation. Retinal capillaries showed increased thickening of the BM, which contained a few cytoplasmic processes of pericytes and electrodense granules. We also detected irreversible occlusion of retinal capillaries by proliferating Müller cells and the absence of endothelial cells and pericytes. These vascular changes and capillary closure in the retinal microvasculature probably became permanent as a result of significant thickening of the BM.

Müller cells constitute an anatomic and functional link between neurons and vessels [41]. These glial cells play a central role in retinal glucose metabolism [53], regulation of retinal blood flow [41] and maintenance of the BRB [51]. Therefore, these factors make Müller cells a target and potential key player in the vascular alterations of the retina, such as vascular permeability. A previous study indicated that Müller cells assemble an acute-phase response, which is associated with retinal up-regulation of the pro-inflammatory cytokine IL-1 $\beta$ [26]. IL-1 $\beta$ induces the recruitment of mononuclear and polymorphonuclear leukocytes that enter the retina predominantly through the retinal vasculature and that appear to migrate through retinal endothelial cells. These results suggest that IL- $1 \beta$ may be an important factor in the pathogenesis of human retinal inflammation [9]. Leukocyte recruitment to the retina caused by IL-1 $\beta$ is essential for inducing breakdown of the BRB, but differs from $\operatorname{TNF} \alpha$, which induces disruption of the BRB [9]. II-1 $\beta$ could play a pathogenic role in the development of chronic ocular inflammation, increasing levels of ICAM-1 and endothelin [21], leukocyte adhesion and breakdown of the blood-tissue barrier $[8,21]$, neuronal death [44], and activation of micro- and macroglial cells [27]. Paracrine interactions between Müller and endothelial cells seem to play an important role in modulating several functions, such as intracellular retinal transport and protection against oxidative stress in retinal capillary endothelial cells. Abukawa et al. [1] demonstrated the possibility that Müller cells may modulate retinal angiogenesis by altering their secretion of TGF $\beta 1$. During the early stage of a chronic ocular inflammatory disorder, pro-inflammatory proteins, such as ICAM-1 and TNF $\alpha$, are up-regulated, and increased leukostasis is observed $[30,38,46]$. These early pathologic changes are associated with up-regulation of VEGF [31, 35, 37]. Müller cell derived-VEGF plays a causative role in retinal neovascularisation, vascular leakage, vascular lesions and inflammation [55]. Differently, PEDF is a major endogenous angiogenic inhibitor in the eye [13], and its role in neovascular diseases has been studied extensively [20, 24, 25]. PEDF was shown to reduce VEGF-induced vascular leakage, implying its involvement in the regulation of vascular permeability [34]. The retinal levels of inflammatory factors, including TNF $\alpha$ and MCP-1 were significantly lower in PEDF-injected eyes than that in the control eyes. In retinal Müller cells, specific down-regulation of PEDF resulted in a significant increase of TNF $\alpha$ production, indicating that PEDF is an endogenous inflammatory inhibitor able to reduce of vascular permeability. PEDF not only reduced VEGF levels in the retina but also decreased retinal VEGFR-2 levels, suggesting that the ability of PEDF to reduce the inflammation and permeability may be ascribed to the down-regulation of VEGF and its receptor [58].

\section{ACKNOWLEDGEMENTS}

The research for this paper was financially supported by Ministry of Health and Fondazione Roma.

\section{REFERENCES}

1. Abukawa H, Tomi M, Kiyokawa J, Hori S, Kondo T, Terasaki T, Hosoya K (2009) Modulation of retinal capillary endothelial cells by Muller glial cellderived factors. Molecular Vision, 15: $451-457$. 
2. Aiello LP, Northrup JM, Keyt BA, Takagi H, Iwamoto MA (1995) Hypoxic regulation of vascular endothelial growth factor in retinal cells. Arch Ophthalmol, 113: 1538-1544.

3. Ashton N (1953) Arteriolar involvement in diabetic retinopathy. Br J Ophthalmol, 37: 282-292.

4. Ashton N (1959) Diabetic retinopathy: a new approach. Lancet, 2: 625-630.

5. Ashton N (1965) The blood-retinal barrier and vaso-glial relationships in retinal disease. Trans Ophthal, 85: 199-230.

6. Ashton N (1970) Pathophysiology of retinal cotton wool spots. Br Med Bull, 26: 143-150.

7. Baglole CJ, Ray DM, Bernstein SH, Feldon SE, Smith TJ, Sime PJ, Phipps RP (2006) More than structural cells, fibroblasts create and orchestrate the tumor microenvironment. Immunol Invest, 35: 297-325.

8. Bamforth SD, Lightman SL, Greenwood J (1997) Interleukin-1-induced disruption of the retinal vascular barrier of the central nervous system is mediated through leukocyte recruitment and histamine. Am J Pathol, 150: 329-340.

9. Bamforth SD, Lightman SL, Greenwood J (1997) Ultrastructural analysis of interleukin-1/j-induced leukocyte recruitment to the rat retina. Investigative Ophthalmol Visual Science, 38: 25-35.

10. Behzadian MA, Wang XL, Windsor $\sqcup$, Ghaly N, Caldwell RB (2001) TGF-beta increases retinal endothelial cell permeability by increasing MMP-9: possible role of glial cells in endothelial barrier function. Incest Ophthalmol Vis Sci, 42: 853-859.

11. Ben-Av P, Crofford $\sqcup$, Wilder RL, Hla T (1995) Induction of vascular endothelial growth factor expression in synovial fibroblasts by prostaglandin $\mathrm{E}$ and interleukin-1: a potential mechanism for inflammatory angiogenesis. FEBS Lett, 372: 83-87.

12. Bianchi $E$, Scarinci $F$, Grande $C$, Plateroti $R$, Plateroti $P$, Plateroti AM, Fumagalli L, Capozzi P, Feher J, Artico M (2012) Immunohistochemical profile of VEGF, TGF-beta and PGE2 in human pterygium and normal conjunctiva: experimental study and review of the literature. Int J Immunopathol Pharmacol, 25: 607-615.

13. Bianchi E, Scarinci F, Ripandelli G, Feher J, Pacella E, Magliulo G, Gabrieli CB, Plateroti R, Plateroti P, Mignini F, Artico M (2013) Retinal pigment epithelium, age-related macular degeneration and neurotrophic keratouveitis. Int J Mol Med, 31: 232-242.

14. Bringmann A, Pannicke T, Grosche J, Francke M, Wiedemann P, Skatchkov SN, Osborne NN, Reichenbach A (2006) Müller cells in the healthy and diseased retina. Prog Retin Eye Res, 25: 397-424.

15. Carmo A, Cunha-Vaz JG, Carvalho AP, Lopes MC (1999) $\mathrm{L}$-arginine transport in retinas from streptozotocin diabetic rats: correlation with the level of IL-1 beta and NO synthase activity. Vision Res, 39: 3817-3823.

16. Cavallotti C, Artico M, Pescosolido N, Leali FM, Feher J (2004) Age-related changes in the human retina. Can J Ophthalmol, 39: 61-68.

17. Choi EY, Santoso S, Chavakis T (2009) Mechanisms of neutrophil transendothelial migration. Front Biosci, 14: 1596-1605.

18. Cogan DG, Toussaint D, Kuwabara T (1961) Retinal vascular patterns. Diabetic retinopathy. Arch Ophthalmol, 66: 366-378.
19. Cunha-Vaz JG (1976) The blood-retinal barriers. Doc Ophthalmol, 41: 287-327.

20. Dawson DW, Volpert OV, GillisP, Crawford SE, Xu H, Benedict W, Bouck NP (1999) Pigment epithelium-derived factor: a potent inhibitor of angiogenesis. Science, 285: 245-258.

21. Dinarello CA (1996) Biologic basis for interleukin-1 in disease. Blood, 87: 2095-2147.

22. Eichler W, Yafai Y, Keller T, Wiedemann $P$, Reichenbach $A$ (2004) PEDF derived from glial Müller cells: a possible regulator of retinal angiogenesis. Exp Cell Res, 299: 68-78.

23. Feher J1, Kovacs I, Artico M, Cavallotti C, Papale A, Balacco Gabrieli C (2006) Mitochondrial alterations of retinal pigment epithelium in age-related macular degeneration. Neurobiol Aging, 27: 983-993.

24. Gao G, Li Y, Gee S, Dudley A, Fant J, Crosson C Ma J-X (2002) Downregulation of VEGF and up-regulation of PEDF: a possible mechanism for the antiangiogenic activity of plasminogen kringle 5. J. Biol. Chem, 277: 9492-9497.

25. Gao G, Li Y, Zhang D, Gee S, Crosson C, Ma J (2001) Unbalanced expression of VEGF and PEDF in ischemia-induced retinal neovascularization. FEBS Lett, 489: 270-276.

26. Gerhardinger C, Biarne's Costa M, Coulombe MC, Toth I, Hoehn T, Grosu P (2005) Expression of acute-phase response proteins in retinal Müller cells in diabetes. IOVS, 46: 349-357.

27. Hanisch U-K (2002) Microglia as a source and target of cytokines. Glia, 40: 140-155.

28. Hockley DJ, Tripathi RC, Ashton N (1979) Experimental retinal branch vein occlusion in rhesus monkeys. III. Hispopathological and electron microscopical studies. $\mathrm{Br}$ J Ophthalmol, 63: 393-411.

29. Jouseen AM, Murata T, Tsujikawa A, Kirchhof B, Bursell SE, Adamis AP (2001) Leucocyte-mediated endothelial cell injury and death in the diabetic retina. Am J Pathol, 158: 147-152.

30. Joussen AM, Poulaki V, Mitsiades N, Kirchhof B, Koizumi K, Dohmen S, Adamis AP (2002) Nonsteroidal anti-inflammatory drugs prevent early diabetic retinopathy via TNF-alpha suppression. FASEB J, 16: 438-440.

31. Joussen AM, Poulaki V, Qin W, Kirchhof B, Mitsiades N, Wiegand SJ, Rudge J, Yancopoulos GD, Adamis AP (2002) Retinal vascular endothelial growth factor induces ontercellular adhesion molecule- 1 and endothelial nitric oxide synthase expression and initiates early diabetic retinal leukocyte adhesion in vivo. Am J Pathol, 160: 501-509.

32. Kaur C, Foulds WS, Ling EA (2008) Blood-retinal barrier in hypoxic ischaemic conditions: basoc concepts, clinical features and management. Progress Retinal Eye Res, 27: 622-647

33. Kern TS, Engermann RL (2001) Pharmacological inhibition of diabetic retinopathy: aminogluanidine and aspirin. Diabetes, 50: 1636-1642.

34. Liu H, Ren JG, Cooper WL, Hawkins CE, Cowan MR, Tong PY (2004) Identification of the antivasopermeability effect of pigment epithelium-derived factor and its active site. Proc Natl Acad Sci, 101: 6605-6610.

35. Lu M, Perez VL, Ma N, Miyamoto K, Peng HB, Liao JK, Adamis AP (1999) VEGF increases retinal vascular ICAM-1 expression in vivo. Invest Ophthalmol Vis Sci, 40: 1808-1812. 
36. Milenkovic I, Weick M, Wiedemann P, Reichenbach A, Bringmann A (2003) P2Y receptor-mediated stimulation of Müller glial cell DNA synthesis: dependence on EGF and PDGF receptor transactivation. Invest Ophthalmol Vis Sci, 44: 1211-1220.

37. Miyamoto K, Khosrof S, Bursell SE, Moromizato Y, Aiello LP, Ogura Y, Adamis AP (2000) Vascular endothelial growth factor (VEGF)-induced retinal vascular permeability is mediated by intercellular adhesion molecule-1 (ICAM-1). Am J Pathol, 156: 1733-1739.

38. Miyamoto K, Khosrof S, Bursell SE, Rohan R, Murata T, Clermont AC, Aiello LP, Ogura Y, Adamis AP (1999) Prevention of leukostasis and vascular leakage in streptozotocin-induced diabetic retinopathy via intercellular adhesion molecule-1 inhibition. Proc Natl Acad Sci, 96: 10836-10841.

39. Miyamoto K, Khosrof S, Bursell SE, Rohan R, Murata T, Clermont AC, Aiello LP, Ogura Y, Adamis AP (1999) Prevention of leukostasis and vascular leakage in streptozotocin-induced diabetic retinopathy via intercellular adhesion molecule-1 inhibition. Proc Natl Acad Sci, 96: 10836-10841.

40. Mohr S (2004) Potential new strategies to prevent the development of diabetic retinopathy. Exp Opin Invest Drugs, 13: 189-198.

41. Newman E, Reichenbach A (1996) The Müller cell: a functional element of the retina. Trends Neurosci, 19: 307-312.

42. Ogawa Y, Yamazaki K, Kuwana M, Mashima Y, Nakamura Y, Ishida S, Toda I, Oguchi Y, Tsubota K, Okamoto S, Kawakami Y (2001) A significant role of stromal fibroblasts in rapidly progressive dry eye in patients with chronic GVHD. Invest Ophthalmol Vis Sci, 42: 111-119.

43. Rodella L, Zamai L, Rezzani R, Artico M, Peri G, Falconi M, Facchini A, Pelusi G, Vitale M (2001) Interleukin 2 and interleukin 15 differentially predispose natural killer cells to apoptosis mediated by endothelial and tumour cells. Br J Haematol, 115: 442-450.

44. Rothwell NJ, Luheshi GN (2000) Interleukin 1 in the brain: biology pathology and therapeutic target. Trends Neurosci, 23: 618-625.

45. Ryan GB, Majno G (1977) Acute inflammation. Am J Pathology, 86: 185-276.

46. Schroder S, Palinski W, Schmid-Schonbein GW (1991) Activated monocytes and granulocytes, capillary nonperfusion, and neovascularization in diabetic retinopathy. Am J Pathol, 139: 81-100.
47. Shakib M, Cunha-Vaz JG (1966) Studies on the permeability of the blood-retinal barrier. Junctional complexes of thr retinal vessels and their role on their permeability. Exp Eye Res, 5: 229-234.

48. Sluiter W, Pietersma A, Lamers JM, Koster JF (1993) Leukocyte adhesion molecules on the vascular endothelium: their role in the pathogenesis of cardiovascular disease and the mechanisms underlying their expression. J Cardiovasc Pharmacol, 22: S37-S44.

49. Smith RS, Smith TJ, Blieden TM, Phipps RP (1997) Fibroblasts as sentinel cells: synthesis of chemokines and regulation of inflammation. Am J Pathol, 151: 317-322.

50. Tannous M, Hutnik CM, Tingey DP, Mutus B (2000) S-nitrosoglutathione photolysis as a novel therapy for antifibrosis in filtration surgery. Invest Ophthalmol Vis Sci, 41: 749-755.

51. Tout S, Chan-Ling T, Hollander H, Stone J (1993) The role of Müller cells in the formation of the blood-retinal barrier. Neuroscience, 55: 291-301.

52. Tretiach M, Madigan MC, Wen L, Gillies MC (2005) Effect of Müller cell co-culture on in vitro permeability of bovine retinal vascular endothelium in normoxic and hypoxic conditions. Neurosci Lett, 378: 160-165.

53. Tsacopoulos M, Magistretti PJ (1996) Metabolic coupling between glia and neurons. J Neurosci, 16: 877-885.

54. Vincent JA, Mohr S (2007) Inhibition of caspase-1/ /interleukin-1beta signaling prevents degeneration of retinal capillaries in diabetes and galactosemia. Diabetes, 56: 224-230.

55. Wang J, Xu X, Elliott MH, Zhu M, Le YZ (2010) Müller cell-derived VEGF is essential for diabetes-induced retinal inflammation and vascular leakage. Diabetes, 59: 2297-2305.

56. Yafai $Y$, landiev I, Wiedemann $P$, Reichenbach $A$, Eichler $W$ (2004) Retinal endothelial angiogenic activity: effects of hypoxia and glial (Müller) cells. Microcirculation, 11: 577-586.

57. Yoshida S, Sotozono C, Ikeda T, Kinoshita S (2001) Interleukin-6 (IL-6) production by cytokine-stimulated human Müller cells. Curr Eye Res, 22: 341-347.

58. Zhang SX, Wang JJ, Gao G, Shao C, Mott R, Ma J-X (2005) Pigment epithelium-derived factor (PEDF) is an endogenous antiinflammatory factor. The FASEB J, 1-21.

59. Zoukhri D (2006) Effect of inflammation on lacrimal gland function. Exp Eye Res, 82: 885-898. 